4. Instead of having examined no terraces, no not one, and found rounded pebbles, etc., I have examined the composition of many, and in the chapter of my work under notice I have stated that the Stockbridge terraces are covered with a reddish loam, mixed with whole or fractured flints, and a considerable proportion of extra-rounded flint pebbles. Yet I have not asserted the marine origin of these terraces, though I believe (with the author of Frost and Fire) that they are "sea-work." I have likewise stated that one of the Llangollen terraces, as revealed by a road-cutting, consists of "a terrace of erosion covered by rounded stones, imbedded in clay and earth." I may add that the Llangollen terraces are more or less covered with an extension of the marine drift of North Wales. I would not have mentioned the apparent refuse of decayed shells in this drift, were it not that Mr. Darwin long ago believed that a similar substance found in drift near Shrewsbury indicated the former presence of sea-shells.

5. Mr. Scrope is evidently not serious when he asserts that one of the Llangollen terraces is close to the railway station, and presumes that $I$ examined it while the train was stopping. The terrace in question is between a mile and a half and two miles from the nearest station, namely, Llantysilio; and I may be allowed to state that I am not in the habit of paying hasty or railway visits to geological phenomena.

6. The discovery of sea-shells in terraces is not an indispensable proof of their marine origin, as undoubted marine drift, in which no sea-shells have yet been met with, may be found extending over whole counties.

In conclusion, I would state that in the Grological Magazinz, nearly four years ago, I inadvertently used the word "raised beaches" instead of raised coast-lines, tidal terraces, or current marks. In my recent work I have not applied the term "raised beaches" to the terraces of the chalk-downs, but have written about them in a very cautious manner, merely expressing opinions, and leaving the question of their origin in a great measure undecided. Neither have I, in the above work, exclusively advocated "marine denudation," but endeavoured to do justice to all parties. The power of fresh-water streams, frost, and ice, $I$ have fully acknowledged (see for instance Recent Atmospheric Action in Snowdonia), though I have regardedthem more as destroyers than originators of the more typical features of the earth's surface.

\title{
INOTIOFS OF MEIMOIES.
}

Sr,-The kindness of Dr. Carl Jelinek, the Editor of the Austrian Meteorological Society's Journal, has enabled me to place at your service the accompanying woodcuts, in illustration of the subjoined translation, which you may, perhaps, think of sufficient interest to find a place in the Grologioal Magazine.

Robrat H. SoOTt.

Methodologioal OfFct, 116, Victorta-gtretet, Westwinster, S.W.

Docember 8, 1869 . 


\section{I.-On some Remarkable Forms of Hatlstones Reoknthy Observed in Georgia.}

[Extract from a letter from Staatsrath Abich to Chevalier W. von Haidinger. From the Journal of the Austrian Meteorological Society, vol. iv.: p. 417.]

I take this opportunity of giving you a preliminary notice of two hailstorms, of both of which I was fortunate enough to be a witness. The phenomena were of so unusual a character that they are well worthy of a full and precise account.

They took place within fourteen days of each other, the first on the 27th May last, at 3 P.M., the second on the 9th June, at 6 P.M. The lucalities were not far asunder, being both in the neighbourhood of Tiflis, near Beloi Kliutsch. The morphological characters of the hailstones, which were very large, as much as sixty or: seventy millimetres in diameter, were as remarkable as they were dissimilar. On the first occasion they were oblate spheroids, resembling Mandarin oranges, while their structure seemed almost organic. On the second there was a fall of actual ice crystals, an occurrence which has never before been noticed, at least, as far as I could discover from the literature within my reach. The stones were not mere lumps, exhibiting indistinct crystalline forms, but spheroidal bodies of definite crystalline structure, overgrown along the plane of the major axis by a series of clear crystals exhibiting various combinations belonging to the hexagonal system. The commonest forms were those which occur in calcite and specular iron. Of the former type, by far the most abundant were combinations of the scalenohedron, with rhombohedral faces; crystals of fifteen to twenty millimetres in height, and corresponding thickness, prettily grouped with combinations of the prism and obtuse rhombohedra. The terminal plane was also occasionally noticeable. Some which fell at the beginning of the storm were flat, tabular, crystalline masses, thirty to forty millimetres in diameter, resembling the so-called "eisen-rose," which occurs at St. Gotthardt.

The stones, when picked up quite fresh, showed sharp edges, with faces which were for the most part slightly curved like those of diamond; however, those which I took to belong to the scalenohedron were perfectly plane.

I was in the open air when each of the storms began, and was able to gain shelter before I received any injury. This was fortunate, for the damage done, even to large trees, was very serious.

I reached home in a quarter of an hour, and found a pail full of the largest stones, which had been collected as soon as the first fright had passed over. My house was not much damaged. I sat down at once and drew ten of these remarkable forms, which had scarcely undergone any alteration.

I have often thought over our conversations about hail, and I see that if I now applied all the theories which have ever been broached to the facts which have come under my own notice, not a single one of them will give me any light towards their explanation. I would ask how such a regular growth of crystalline masses, reminding us 
in their character of the drusy crystals of calcite from Andreasberg, can be reconciled with the violent atmospheric commotion which we suppose to accompany the formation of hail. We say in naturâ nihil fit per saltus, and I believe it. The growing crystalline mass must have been suspended for a long time in a very cold stratum of aqueous vapour before it reached the earth.

[The two subjoined cuts are copied as closely as possible from the original drawings.]

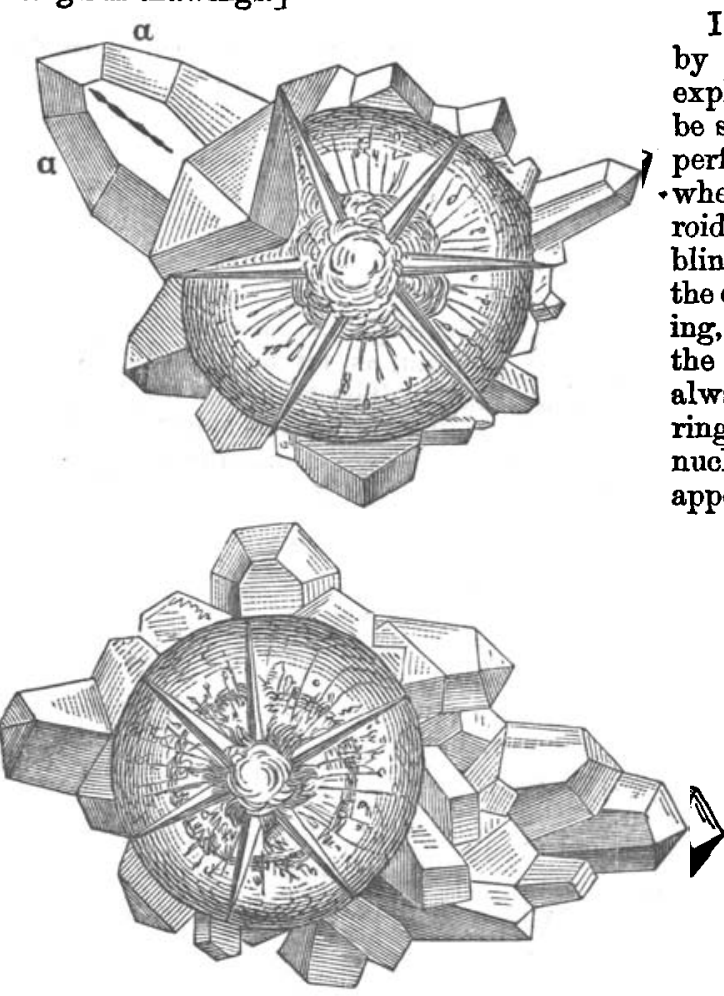

Actual representations (of the natural size) of two of the Hailstones which fell in Georgia on the 9th June, 1869, drawn at the time by Btantarath Abich.

I would only add, by way of a hint, to explain what cannot be shown by such imperfect drawings, that - where the flat spheroidal forms, resembling specular iron, in the centre of the draw ing, exhibit shading, the crystals were not always opaque. The ring surrounding the nucleus had a milky appearance, owing to small air bubbles, as had the nucleus itself in most instances. Many of them, however, had a clear nucleus. This could easily be seen next morning, when the stones had all melted down to cakes of about an inch in diameter, occasionally taking the shape of a regular hexagon.

The milky ring round the central point was clearly distinguishable as a sort of fibrous web composed of the finest air cavities traversed by threadlike pores. In some cases there was no ring, and the nucleus was semi-opaque.

The shading round the border of the large circle is only intended to mark the smooth spheroidal form of the central mass. The actual crystals were attached parasitically to its edge, or else inserted in a sort of socket, as I found when the stones thawed down. (See $a$, Fig. 1.) 
All the stones contained fine air pores, pear-shaped or worm-like, ruming from the centre to the circumference. The drawings are as near as possible natural size.

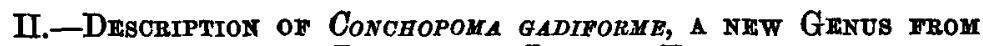 thin Perminan of Lebach, Eto.}

By Professor Krer, of Vienna. Abstracted by Dr. Chr. Lürtken.

[Kner: Ueber Conchopoma gadiforme, n.g., und Acanthodes ans dem Rothliegenden (der untern Dyas) von Lebach bei Saarbrücken in Rheinpreussen. Wiener Sitzungsberichte. Ivii. bd. 1868.]

T 1 fourth of their total length, but in the larger hardly one-fifth; it was at least as broad as high, or even broader; the mouth was terminal. Both jaws were armed, in the middle, with a single series (rarely several) of pointed teeth; the vomer and palate were paved with a series of larger, thicker, partly globular, partly obtuselypointed, crushing teeth ; a similar series of teeth was directly opposed to it below, probably placed on the hyoid bone; the palatine bones had also, apparently, a narrow longitudinal band of similar teeth. The upper part of the head was covered by thin plates radially furrowed. The eye, apparently small, was situated laterally, near the anterior end of the snout. The branchial fissure was covered by (probably two) conchiform opercular bones, one (by far the larger), the principal opercular bone, has its umbo directed upwards; the other and smaller one appears to have its umbo pointed downwards. The scapular arch was formed of a broad strong humerus, to which were attached the hroad clavicular plates, uniting on the throat in such a manner as to form an angle with each other, as is the case in many Siluridoe and Loricarine. The branchial arches were broad, channel-shaped bones; the branchiostegous rays rather short and thin. The anterior part of the trunk was higher than the head, and the general outline reminded one, especially by the high and long peripherical (dorsal) fin, of the Pleuronectidae. The dorsal fin, however; commenced beyond the middle of the total length, and extended backwards, lowering rapidly towards the tail point, immediately opposite the similarly constructed anal fin, near to which the rather small, few-rayed ventrals were affixed. The numerous slender articulated rays of the dorsal fin were supported by long, slender, hollow interspinous bones, reposing on similar spinous processes. The pectorals were attached behind the "shoulder-girdle," or scapular arch, about mid-way between the dorsal and ventral line, and were longer than broad, and many-rayed.

In the vertebral column the osseous centra were altogether wanting, and the notochord extended in a broad and rectilinear course to the very point of the tail; superior and inferior narrow arches were only partially developed, and the spinous processes were remarkably long and slender, as in Coelacanthi, forming hollow tabes, as do also the numerous ribs.

The whole trunk was covered to the very edge of the fins by amall 


\section{Reviewos-Desor's and Loriol's Échinologie Helvétique.}

and thin scales without enamel, mostly of a lengthened rhomboid shape, but varying considerably, being sometimes equally high as long,-sometimes, especially towards the dorsal and ventral profile, considerably longer than high, and losing the rhomboidal shape, and produced into a point. The greatest differences in size and shape are observed on the abdomen, behind the clavicular plates, where the crowded and delicate longitudinal striæe and furrows are replaced by ridges, radiating from an eccentric centre, calling to mind the covering of the thorax in many Loricarina. The lateral line runs parallel to the vertebral column, and has left behind the impression of the rather wide and long tubes, that may be seen towards the point of the tail.

The description is illustrated by four plates. On the affinities of this interesting fossil genus Prof. Kner gives no decided opinion; but the writer cannot refrain from asking, should this not be the Coelacanthus Munsteri of Agassiz, of which a description was never published, but was stated by Prof. Huxley to be a peculiar extinct type allied to Phaneropleuron? In the second part of his paper (also with four plates) Prof. Kner dwells on the structure and characters of the Acanthodes of Lebach, adding to, and correcting in many important points, the contributions to our knowledge of this genus given by Troschel and Roemer. But as an abstract of this part of the Memoir cannot well be made, I shall refer palæichthyologists to the original paper itself, and only venture to insert here a sketch of

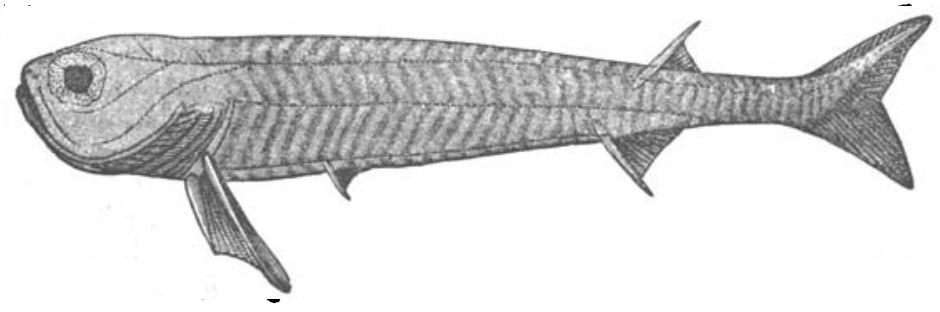

a restored Acanthodes, based on the restoration of Roemer's and Kner's corrections, as a sort of graphic summary of our actual knowledge of the genus.

\section{E耳VI正WS.}

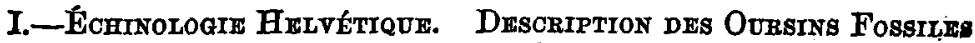
de ia Sutsse par E. Desor ext P. de Lortol. Iv. I., II., III. Tabl. XII. Reinwald, Paris, and Kreidel Wiesbaden, 1868.

DAL ZEONTOLOGISTS have long been impressed with the importance of the study of the Echinodermata to the progress of Geology, for the marked differences between the forms of these fossils found in layers of different ages had long attracted the notice of observers. It is now upwards of forty years since Goldfuss gave, in the Petrefacta Germanio, admirable figures and good descriptions 